\title{
TEACHING FRACTIONS TO PRIMARY SCHOOL STUDENTS WITH VIDEOGAMES - A COMPARISON BETWEEN INSTRUCTIVIST AND CONSTRUCTIONIST APPROACHES
}

\author{
Ana C.R. Martins, Lia Oliveira \\ Instituto de Educação da Universidade do Minho (PORTUGAL)
}

\begin{abstract}
There are two key lines of research studying the effects that educational games have on students' knowledge acquisition and motivation: one focusing on instructivist pedagogical strategies (placing students in the role of players) and one aiming constructionist ones (placing students in the role of educational game designers). There are scarce studies comparing the two strategies, with initial results indicating that the constructionist approach may bring greater benefits.

Our research question is then the following: are there any differences in knowledge acquisition and motivation between students that design educational games and students that play educational games? Our results suggest that a constructionist approach might have a greater impact both on knowledge and motivation. Our paper describes a pilot study focusing on teaching fractions to elementary students using two different pedagogical strategies, instructivist versus constructionist, with videogames as instruction tools, in an informal learning environment.
\end{abstract}

Keywords: Educational games, constructionism, instructivism.

\section{INTRODUCTION}

In the last decades there has been an increasing focus of attention towards the use of videogames as teaching and learning tools. Examining the research published so far within this subject, one can identify, as other authors have done, e.g. [1], [2], two main distinct lines of investigation, related to two different approaches to the use of videogames in education, both with promising results. The more established line of research tries to uncover the effects that the act of playing a videogame may have on students' knowledge acquisition and motivation, and it is aligned with an instructivist perspective on the use of games for learning. The second, more recent, line of research focus on understanding the effects that teaching game design to students may have on their knowledge acquisition and motivation, which is aligned with a constructionist perspective. There are still few studies that compare these two pedagogical strategies [3], [4], with initial results indicating that the constructionist approach (placing students in the role of educational game designers) may have greater benefits than the instructivist one (placing students in the role of players).

The work described in this paper is part of a larger project that aims at investigating student's authoring of educational games as a pedagogical strategy, and its impact on their learning and motivation. The majority of studies conducted so far with students authoring educational games focus on middle school students with no distinctive features [4], [5], [6], [7]. We are particularly interested in students at-risk of school failure or abandonment since we believe this can be a useful teaching strategy for those cases. We also want to explore how this approach can be developed with children as young as seven years old in order to contemplate early interventions.

When defining what content knowledge to use for the present study, an exploratory study, we opted to address fractions, for the following reasons: 1. Rational numbers, and particularly fractions, is considered a complex topic to teach and learn; 2. Primary school curriculum has recently underwent changes in Portugal, e.g. anticipating the introduction of rational numbers as a measure of length and the representation of fractions in a number line, from the third year to the second year, with profuse disapproval from teachers; 3 . Treefrog Treasure game, from Center for Game Science [8], which we consider a well-developed educational game teaching fractions, inspired us to also use that content knowledge.

Our research question is the following: Are there any differences in knowledge acquisition and motivation between students that design educational games and students that play educational 
games? To assist in answering it, our paper describes a pilot study focusing on teaching fractions to elementary students using two different pedagogical strategies, instructivist versus constructionist, with videogames as instruction tools, in an informal learning environment.

\section{METHODOLOGY}

\subsection{Setting and participants}

This study took place in the Center for Social Intervention Studies (CESIS), a centre that helps children and youth through study support, counselling and promotion of social, cultural and ludic activities, in Bairro do Zambujal, a social neighbourhood in the Lisbon suburbs.

Our sample is composed of two groups of five elementary students each (two fourth graders and three third graders, per group), with ages ranging from seven to ten years old. These are considered students at-risk of school failure or abandonment due to their socioeconomic conditions. They attend schools included in the national program of Educational Territories of Priority Intervention (TEIP), schools that are located in economically and socially disadvantaged territories, marked by poverty and social exclusion, where violence, indiscipline, abandonment and school failure are significantly manifested.

The content knowledge used was mathematical fractions, with the learning objectives selected from the Portuguese national curriculum goals for elementary school.

The first author of the paper guided the sessions, thus assuming the role of a partaking researcher.

\subsection{Game authoring software}

On deciding which game authoring software to use, the following points were considered priorities: 1. Software with a simple interface that could be explored by elementary school children; 2 . Authoring tools with no need to code or write and that did not focus on teaching to code; 3 . Since it would be software from a foreign country, it couldn't have much text, as Portuguese children of the target age are not familiar with the English language; 4. Free, so it could be used by underprivileged children and in the context of projects, associations and schools with limited funds.

Taken all of the above into account, we selected Blockstud.io [9]. Blockstud.io is a game authoring tool with a simple interface, requiring no writing or programming skills, which links behaviour to colour. To define the games' rules the author has to put his game in play mode and exemplify, through drag and drop, what he wants to take place as a result of a particular event (be it a player input or a collision) which is then saved as a rule for every game screen.

To approximate the games the participants would play with the ones they could create or modify, we decided to also use Blockstud.io to develop the games played during the study. We designed and developed five games to teach a set of curricular goals selected by being considered both utmost important learning objectives and significant difficulties for the participants (based on observations made during the first session).

Each participant was assigned a personal account in Blockstud.io were he had access to the games developed for the sessions as well as the editing tools.

\subsection{Timetable and proceedings}

During five weekly sessions of approximately one hour per group, we implemented an after-school programme of activities. In the first session both groups were asked to complete a written assessment that tested their knowledge on fractions and their motivation (see section 2.4 for more details). In the second session, due to the participants' difficulties in the content matter, they were given explanations about fractions, encouraged to contribute with their knowledge and asked to complete worksheets to help them better understand the subject; they started playing games about this topic as well. In the third session both groups played the same games, but the game-authoring group also began exploring Blockstud.io editing tools. In the fourth session, the game-authoring group planned their adaptation of one of the games available, using paper and pencil, and then started to modify the pre-existing digital model of that game; the players group had the whole session to play all levels of the five games. In the fifth session, both groups were tested again on their knowledge and motivation, and all the participants were asked to evaluate the sessions. 


\subsection{Data Collection}

The study included participated observation, and the observations and notes of the partaking researcher were used for analysis.

Both groups were given the same written test in the first and the last session. The test was validated by a primary school teacher and consisted of two different sections: 1 . The first section examined the participants' knowledge on fractions through questions selected (from previous national exams' question banks and from Khan Academy) to evaluate the national curriculum goals for the second and third grades; 2 . The second section used a four-point adapted Likert scale to measure the participants' motivation towards mathematics, fractions, teaching, learning, playing games and creating games. The test in the last session differed from the first one only by including an extra section concerning the participants' evaluation of the activities' programme conducted during the study; it consisted of a fourpoint adapted Likert scale, and of open-ended questions that inquired what the participants liked more and why and what they liked less and why. The four-point Likert scale was adapted to the target age; it contained four cartooned faces, being the boundaries a face looking sad and crying (value 1) and a face with a radiant smile (value 4 ).

The materials created by the participants were also analysed.

\section{RESULTS AND DISCUSSION}

\subsection{Games developed for the study}

We developed five digital mini-games, each with four levels. To progress in each game, the player has to correctly solve the challenges that appear in each level. If the player fails to solve a proposed challenge, he is then directed to an intermediate screen with an explanation, and has to start over from the first level. Due to software constraints, which limit the possibility to provide in-time detailed feedback, this design decision was made to take into account the play method of solving challenges uncritically and unknowingly by trial and error. This was done after the first session when we observed that one of the participants was progressing based on lucky trials with no significant knowledge achievement. Knowledge acquisition and learning goals were scaffold throughout the levels of each game.

On the first session it became clear that the participant children had several difficulties regarding fractions' content knowledge. As they didn't know that they could only apply the designation "fraction" when an all was divided in equal parts, and they strived in identifying if a geometric figure was split in equivalent portions or not, we created a game, named "Equal Parts", to facilitate learning this matter. In "Equal Parts", the player navigates an avatar (blue man), using the arrow keys, and has to eat (collide with) all chocolates (brown rectangles) that are in deed divided in equal parts (see Fig. 1).
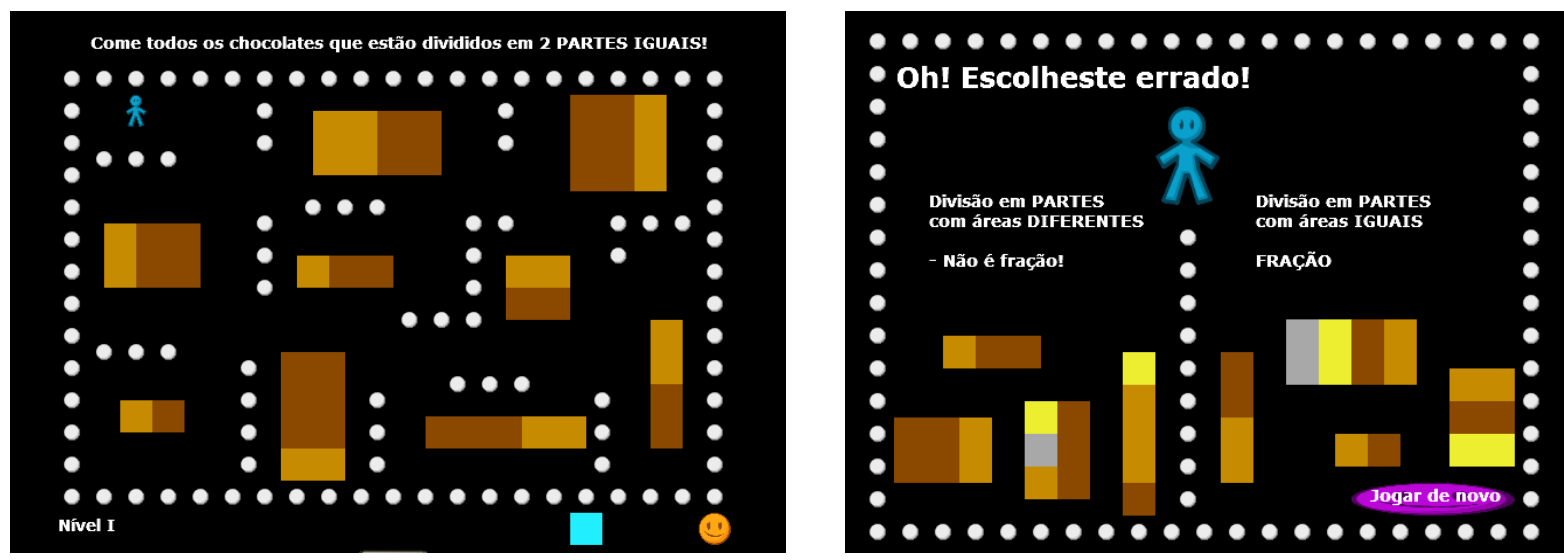

Fig. 1- Screenshots of "Equal Parts". Left: level one. Right: game screen displayed upon failing.

This game was important for participants' understanding of the central idea of fractions as parts of an all divided in equivalent shares. The students enjoyed playing it and both the worksheets they completed afterwards and their comments while playing indicated that the game "Equal Parts" was helpful in promoting the desired learning goal. 
In order to teach the notion of fraction as a measure of length, its representation in a number line, and its matching with a portion of a geometric figure divided in equal parts, we created the games "A Half" and "A Third" (see Fig. 2). In both games the player navigates an avatar (grey mouse), using the arrow keys, and has to eat (collide with) a piece of cheese to pass the level. To get to the cheese the player has to open a door, a blue rectangle representing a line segment, with several dots on behalf of locks. To open the door he has to understand the code (in the form of a written fraction) that points to which of the locks he should use (i.e. when the mouse collides with the dot that equals the specified fraction then the door opens). In some of the levels, the player also has to collect rectangles that represent the fraction given as the door code.
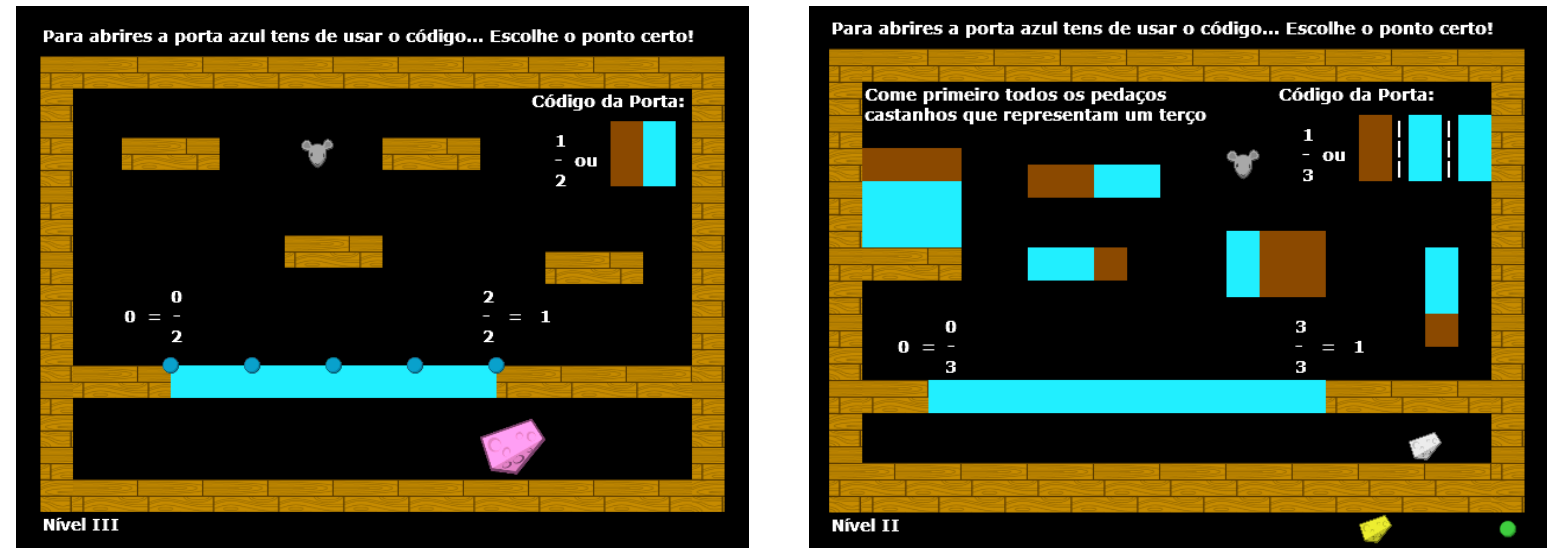

Fig. 2 - Games' screenshots. Left: "A Half”. Right: "A Third”.

One of the challenges children had while playing these games was identifying fractions in geometric figures without explicit lines dividing the figures in parts. For example in level II of "A Third" (Fig. 2, right screenshot) some of the rectangles have two thirds painted blue and one third painted brown, but without explicit lines dividing the blue part in two (to clearly show each third of the rectangle), children were not able to select the rectangles that had a third painted brown. They frequently asked for assistance from the researcher but usually after an explanation using pencils or sheets of paper to divide the figures displayed on the game screen, most were able to progress in the game. We recognize that this design decision introduced an extra layer of complexity to the game, which might be discarded in future work.

From the initial session it became apparent that children had more difficulties when exposed to the notion of fractions as parts of a group of discrete identical objects, so we designed two games to explore this concept, "Rocket" and "Paint the Fraction" (see Fig. 3). In the game "Rocket" (Fig. 3, left) the player has to navigate a rocket (using the arrow keys) and visit the planets that have a particular fraction of its rocks precious (represented by the colour orange) and collect them. In the game "Paint the Fraction" (Fig. 3, right), players have to paint (click on) the number of elements of a group (hearts, circles or rocks) matching a given fraction.
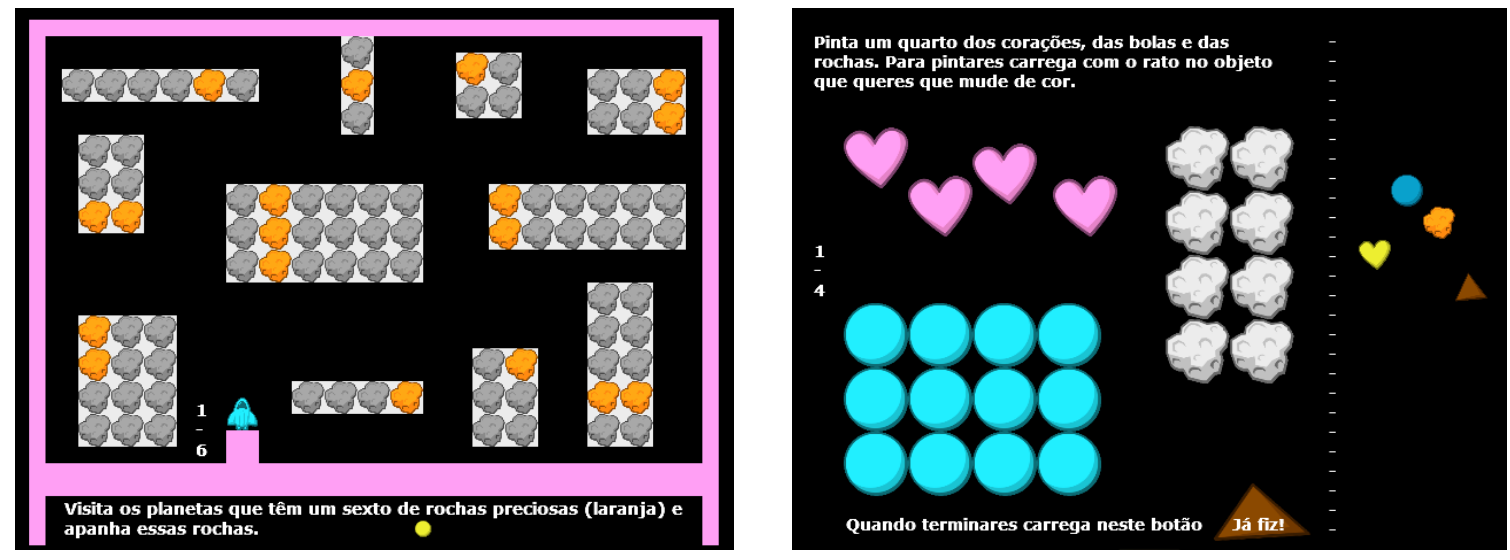

Fig. 3 - Games' screenshots. Left: "Rocket”. Right: "Paint the Fraction”.

While participants were playing these games it became clear the difficulties they had performing divisions, particularly amongst third graders. The approach carried out in order to overcome this, was 
to teach them to identify the number of parts in which they had to divide the group of equal objects and then write down the multiplication table for that number, until they reached a result equal to the number of objects displayed. Both games were beneficial to explore these difficulties, make the children aware of their existence and serve as motivation to devote effort in trying to overcome them.

On the game "Paint the Fraction" one child discovered that if she painted the exact number of objects to align the respective markers displayed on the right part of the screen, she would win in each level. So we had to sit down with her and ask her to repeat parts of the game while explaining the rationale behind what she was doing.

During play sessions, in general, we observed that some of the participants, especially the ones from third grade, sometimes struggled with using the keyboard and mouse to access their account in Blockstud.io and to navigate their avatars. In all the games, participants were very frustrated every time they failed and had to start over from the beginning, particularly when it was due to lack of dexterity in using the commands.

\subsection{Games developed by study participants}

In the third session, students from the constructionist approach were exposed to the editing functions of Blockstud.io through a set of written instructions that requested them to create a game screen with different blocks, colours, shapes and text, while being supported by the researcher. Students usually didn't want to look at the instructions, striving to read and interpret the text, even when it consisted of small sentences and images. They would generally ask what they had to do even before starting to read the directives. In this session, students created drawings using the set of tools available in the authoring software in order to get accustomed to it (see Fig. 4).
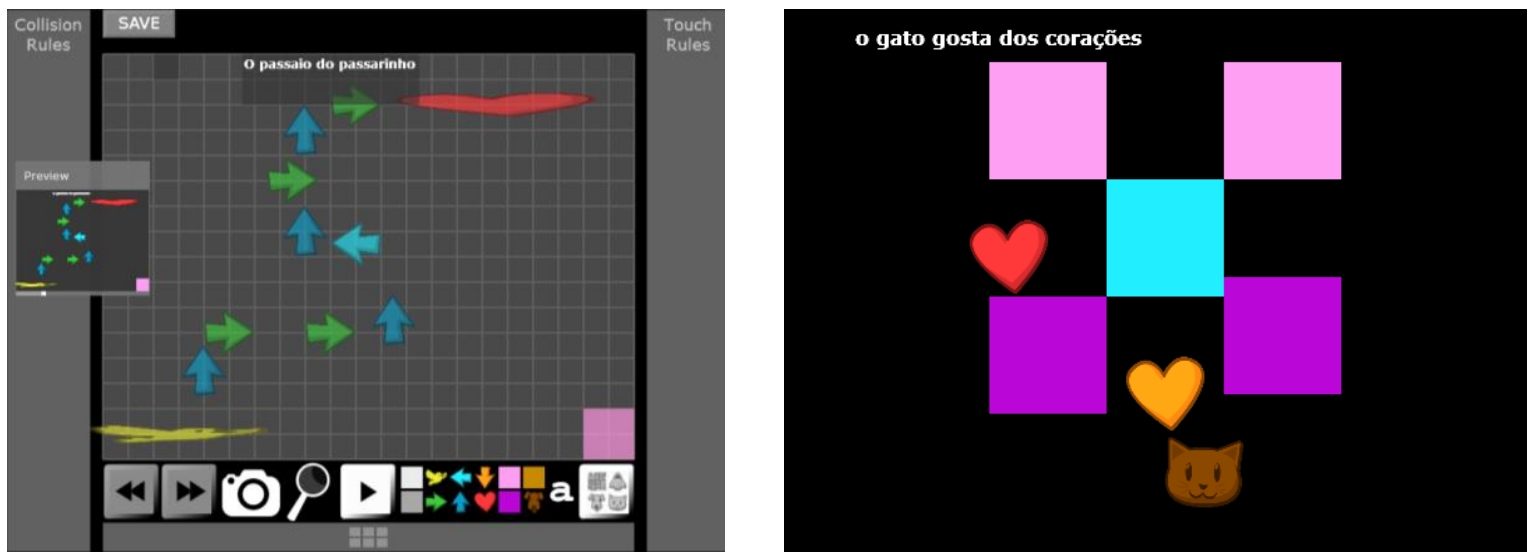

Fig. 4 - Screens created by students using Blockstud.io. Left: editing mode. Right: play mode.

Due to time constraints participants of the constructionist strategy didn't have the chance to go through the ideation process to create a game from scratch. Neither was there time to learn and explore the creation and editing of game rules. Instead, they used the model of the game "Paint the fraction" and chose how many and which shapes they would use in their version of the game. We selected "Paint the Fraction" as the game to modify because the majority of participants liked this game and because it was the easiest and fastest model to alter. For that, the participants began by using paper and pencil to draw a number of pre-determined shapes and to calculate how many of them they would have to paint in order to match a pre-determined fraction (see Fig. 5).
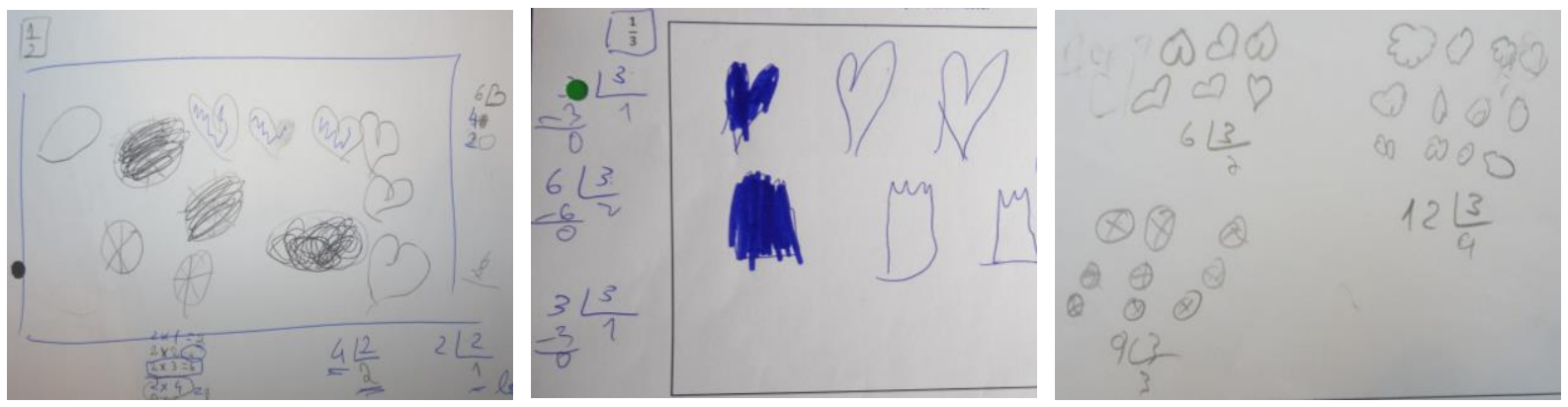

Fig. 5 - Materials created by students while preparing to modify "Paint the Fraction". 
Students were then given access to the digital game "Paint the Fraction" in editing mode so they could alter the shapes of the objects (for example, they changed the hearts, rocks and circles of the original game into birds, cats, mice, fishes and rockets). They also chose how many elements of each group they wanted to display on the screen and they had to know how many of them should the player paint (click on) to pass the level, i.e., how many objects in each group represented a half or a third. Those decisions were then implemented into the pre-existing game model as can be seen in Fig. 6.
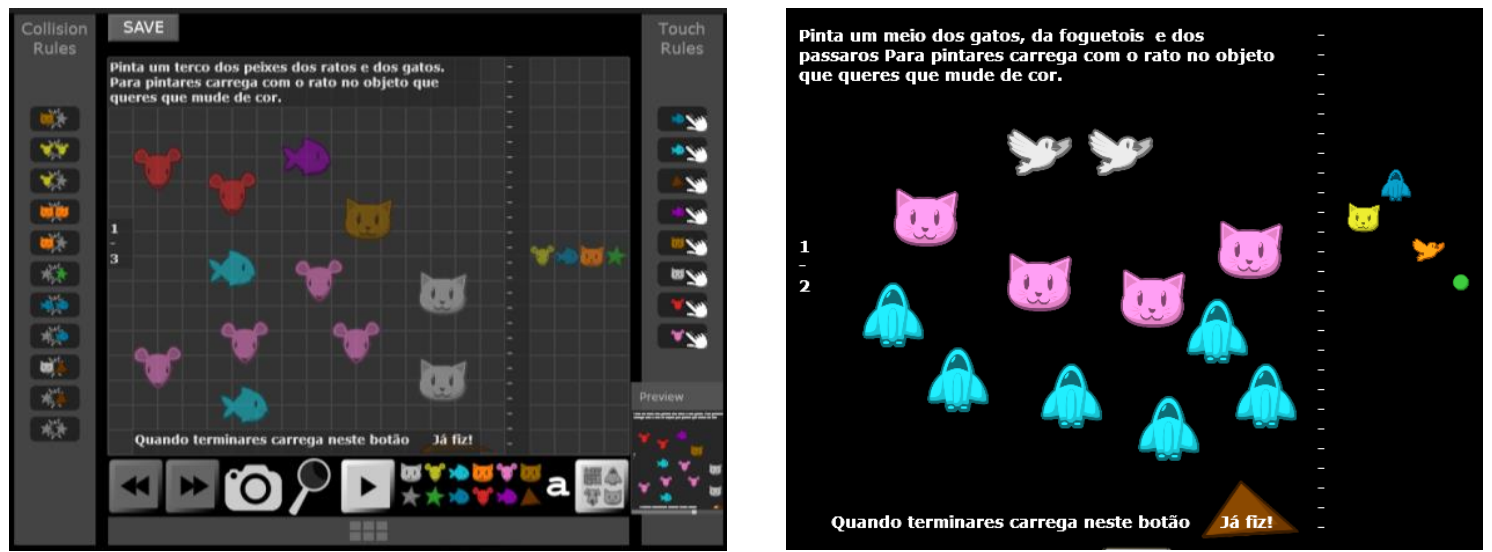

Fig. 6 - Students' versions of the game "Paint the Fraction". Left: editing mode. Right: play mode.

Students enjoyed the fact that they could customize the game according to their preferences. They showed interest in creating other changes in the game, like altering colours (which are linked to behaviour thus to game rules) but due to time limitations this was not possible during the study. The third graders were not able to implement their designs (created with pen and paper) in the game's digital model in Blockstud.io since they used all the available time to work on their difficulties performing divisions in order to complete their paper design of the game challenge.

We think that it would be beneficial to extend the time allocated to the activities of game authoring within the constructionist group.

\subsection{Knowledge tests}

For knowledge, motivation and sessions' evaluation scores, only eight children were included (four in each group) since two of them didn't attend the last session.

We observed that students had limited autonomy and requested assistance frequently.

Overall children found the test difficult and were frustrated both by not knowing how to answer and by the fact that the researcher didn't give them the right answer or corrected their answers on-demand. Though initially the researcher's intervention during the tests was planned to be limited to facilitate the understanding of the questions, it soon became clear that without content help or hints, the students' attitude towards the test would undermine the acquisition of data. All hints provided were accounted for while grading the knowledge tests, with a penalization in each question's score for hint given.

We observed changes between the initial and final test sessions in participants' knowledge, attitude and confidence. In the last session, students' showed more confidence in their ability to complete the test and though some of them asked for more hints than in the first test (initial number of hints asked for: average - 9.5, standard deviation - 6.7; final number of hints asked for: average - 12.6, standard deviation - 10.3), this may reflect both an increase of the students' interest in completing the test and a closer relationship with the researcher (which might have put the participants more at ease during the final test). Overall growth in content knowledge was observed during the sessions through worksheets completed, children's inquiries and answers. Test grades by participant are plotted in Fig. 7, and they also point to a general improvement, though being relevant to note that the standard deviation increased from 6.9 to 12.6 . 

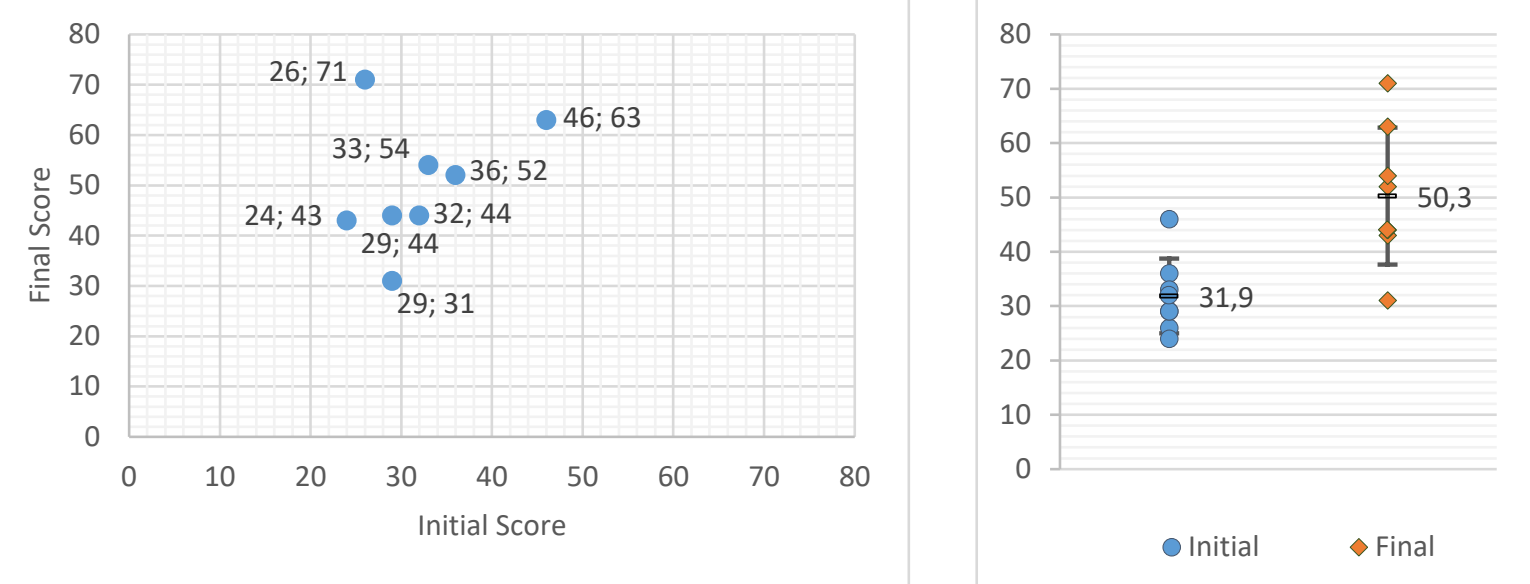

Fig. 7 - Knowledge test classification, initial versus final scores; each dot represents a child.

We then computed the test score differences (final score minus initial score) as percentage of variance from the initial grade, and plotted it against category: Instructivist Strategy versus Constructionist Strategy and Third Graders versus Fourth Graders (see Fig. 8).
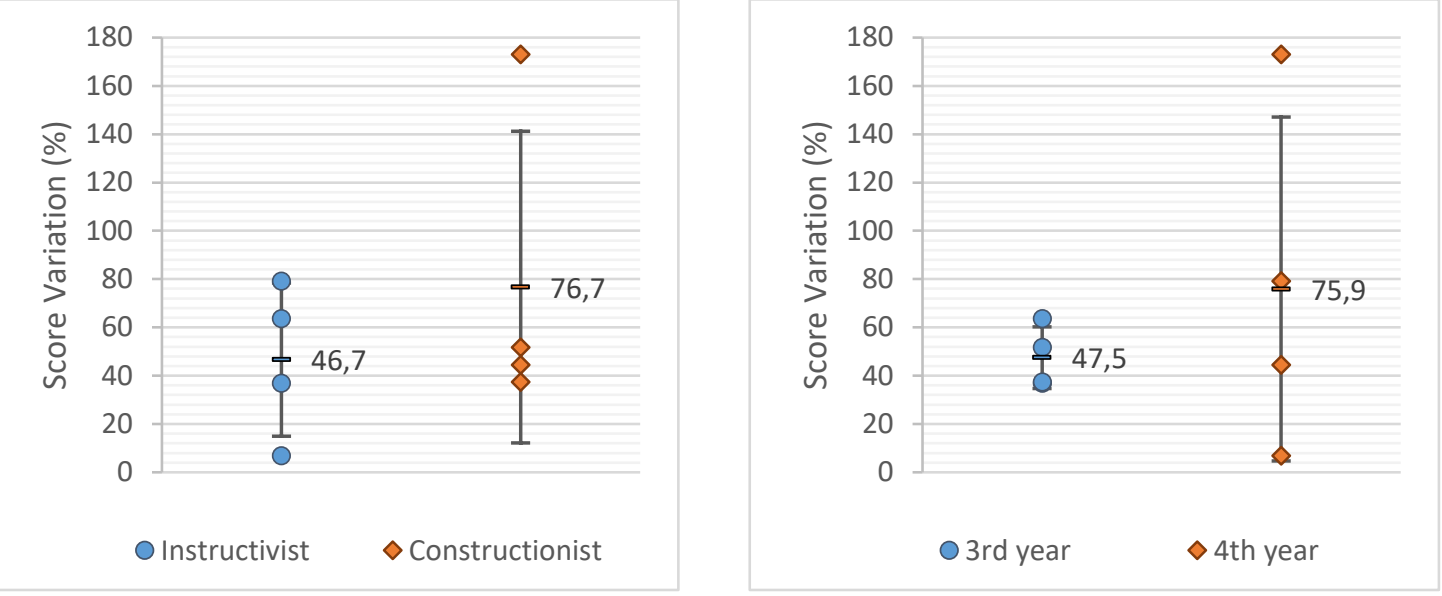

Fig. 8 - Test score as percentage of variance from initial grade. Left: children grouped by teaching strategy used. Right: children grouped by school year.

From our observations we noted a higher attainment of knowledge in the constructionist group, especially in one of the participants for whom this intervention was highly successful. The test results are aligned with our observations, suggesting a greater effect on students' knowledge acquisition in the case of the constructionist teaching strategy, though with a larger standard deviation than in the instructivist group.

We have observed differences in knowledge acquisition between third and fourth graders only in the sense that the fourth graders were more familiarized with the content matter and had their autonomy and working skills more developed than the third graders. The test results suggest that the fourth graders might benefit more from the use of educational games as learning tools than the third graders, though it is important to keep in mind the high standard deviation.

Overall we observed that, while playing, all students profited the most from guided play, in which the researcher asked them to stop, think and explain their doubts and the rationale behind their actions.

\subsection{Motivation tests}

We did not detect significant differences in engagement between the instructivist and constructionist groups. We did notice however that while fourth graders were usually more independent, they were also less interested or motivated to learn.

In the first session, when asked upon orally, almost all students said they liked to play games and showed enthusiasm about it. This changed a little throughout the sessions, particularly within the 
instructivist approach and the fourth graders. This may have to do with students being more used to non-educational digital games and usually being less exposed to educational digital games, which differ in their purposes, length and aesthetics; they might have had high expectations in the beginning that might have not been met throughout the sessions. In the first session when asked upon orally if they had ever created a game, participants answered no and looked surprised at the possibility of creating games themselves.

To complement our observations, we used the scores attributed by the participants in the test section related to motivation. For each group we computed the average variation between final and initial values as a percentage of the value attributed in the first session (see Fig. 9).

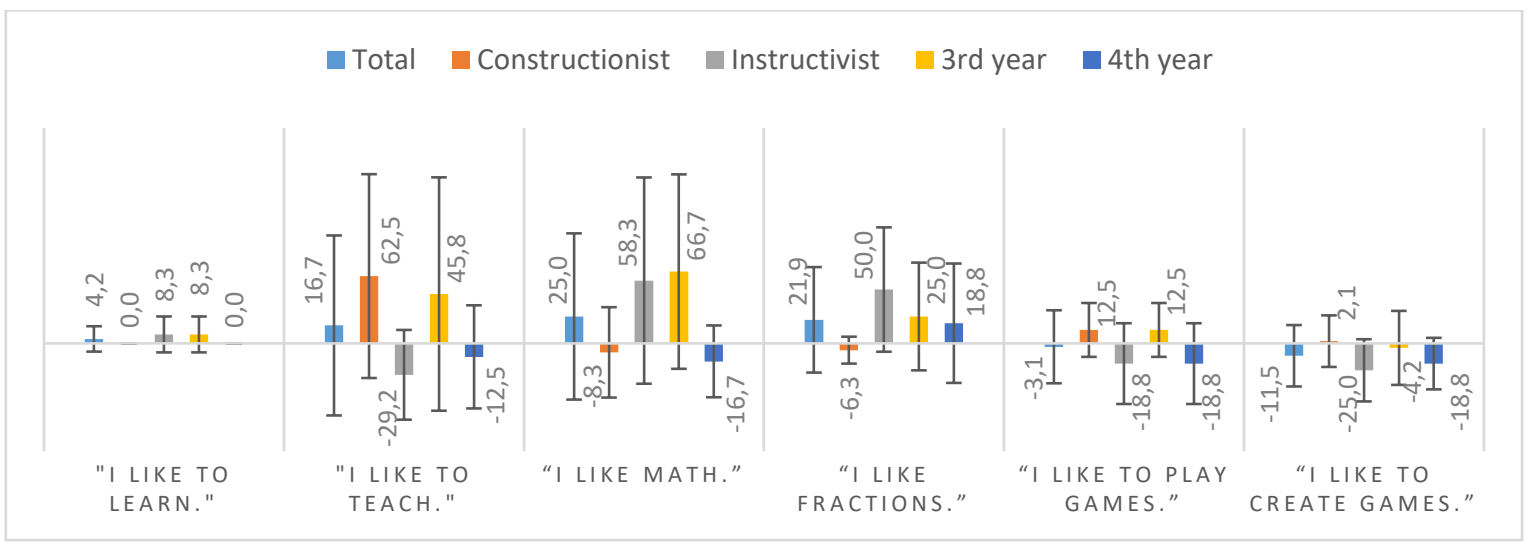

Fig. 9 - Motivation test results, variation between final and initial responses in percentage.

Thought we didn't detect pronounced differences in motivation between the two pedagogical strategies, motivation test results indicate that the constructionist group highly increased its motivation towards teaching, increased its motivation towards playing games and slightly towards creating games, contrasting with the variation seen for the instructivist group regarding those dimensions, which was negative. On the other hand, the instructivist group increased its motivation towards math and fractions, with the constructionist group's motivation showing smaller deviation in the opposite direction. Third graders increased their motivation in every dimension except towards creating games, while fourth graders decreased their motivation in all dimensions except towards fractions.

Throughout the study we observed both intrinsic motivation ("I want to create something I like", "I want to learn more", "I want to complete this game") and extrinsic motivation ("I want to be better [or faster] than my colleagues", "I want to please [the researcher]").

We were able to observe competition both positive, in the sense that participants wanted to progress faster than their colleagues, and negative, e.g. one of the children gave up when she saw she was far behind in finishing the games, and sometimes students mocked colleagues that were falling behind in a game or level completion. We also observed collaboration both positive, e.g. "do you want me to tell you how to pass that level?", "can I explain that exercise to student X?", and negative, e.g. when students wanted to give quick pass answers to their colleagues without letting them think or without explaining to them why a given answer was the right one.

\subsection{Sessions' evaluation}

In the last session students were given an extra section in the written test that aimed at collecting their evaluation about the activities developed during the study.

For the total number of participants, the sentence with a higher value in the modified Likert scale was "I feel that I have learned more about fractions", with an average of 3.8 (in a four-point scale) and a standard deviation of 0.5 (the smallest). The sentence with a lower average value (3.3) was "I would like to have had more sessions", also being the one with a larger standard deviation (1.4). This is interesting since though during sessions students would complain frequently about the work they had to do, they showed sadness when they realized we had come to the last session, and some of them asked why we couldn't continue.

We then decided to compare session's evaluation between the two groups exposed to different pedagogical strategies (see Fig. 10). The results indicate that for every dimension, the constructionist group attributed a higher evaluation than the instructivist one. 


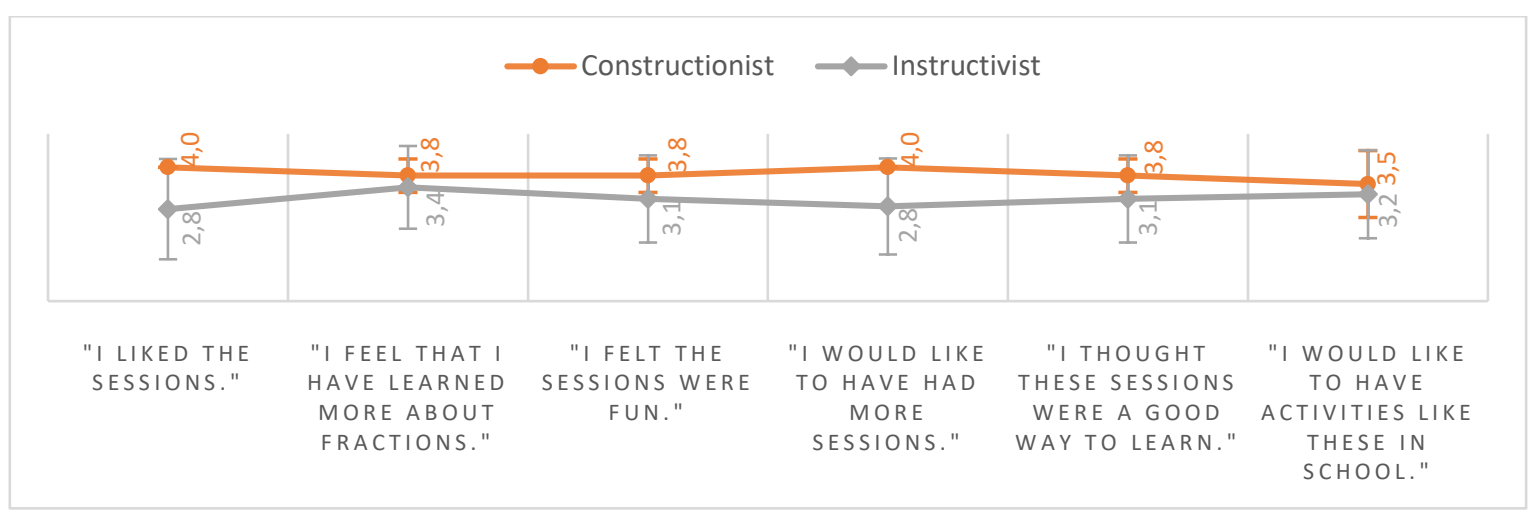

Fig. 10 - Sessions' evaluation from groups exposed to different pedagogical strategies.

To complement our observations, suggesting that third graders seemed to have a more positive outlook towards the study than fourth graders, we compared the average evaluation scores given by groups of different school years, with the results corroborating our observations (see Fig. 11).

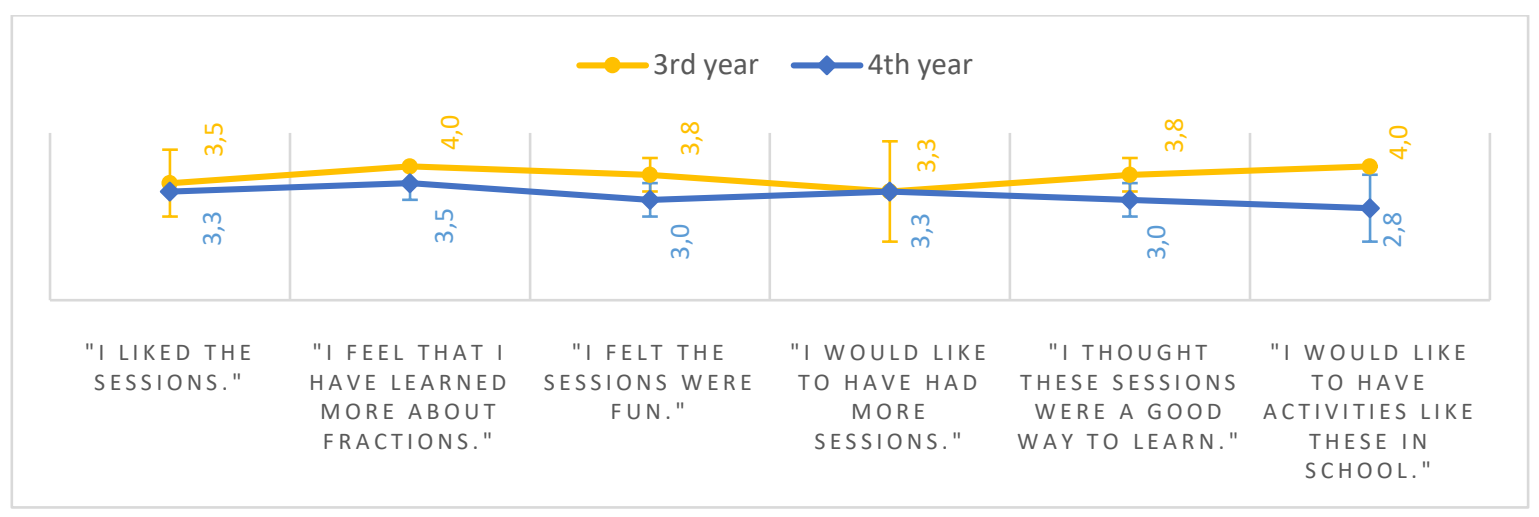

Fig. 11 - Sessions' evaluation from groups of different school years.

Participants showed interest in doing the same type of activity with other school matters, e.g. a student asked if we could also play games about science/environment because she liked that school subject very much. Interestingly, other students that frequented the centre where the study took place, but that were not part of the project, showed interest towards the activities developed during the study, and at least four of them, from the fifth grade, asked if they could join (with one of them asking it more than once). This manifestation of interest was probably influenced by their conversations with the participating colleagues and their curiosity towards the games that were played during the sessions.

\section{STUDY LIMITATIONS AND FUTURE WORK}

Overall this study has a strong qualitative component. Though quantitative data is presented, it is essential to state that data interpretation must be extremely cautious due to sample size, which is the prime limitation in this study.

There are possible confounding effects in our results. One of them is the effect of testing; the fact that students had taken a test previously might lead to better performance in the post-test. Other effects include the desire to please the researcher while evaluating the sessions, not understanding what was asked of them on the Likert scale questions, or their different motivations to attend the study, e.g. one of the participants came specifically to the centre for our sessions (it was not her day to have activities at the centre), which might have affected her motivation towards the study in a negative way. The fact that we had students from different school years can be seen as an advantage regarding the sessions' dynamics (with older students helping younger ones) but in a small sample it can also confound the results.

Due to time constraints students didn't have the chance to go through the ideation process to create a game from scratch. Neither was there time to learn and explore the conception and edition of game rules. We think it would be very interesting to explore this in future research with more time per session and/or more sessions. Since it was the students' first time designing computer games with 
Blockstud.io, they had technical difficulties to implement their ideas so we think it would also be beneficial to dedicate more time to explore the game authoring software.

Considering that students found the knowledge test very difficult, it might be useful to construct an easier test for future studies, thought the questions asked were aligned with the national curriculum knowledge goals. Also, it can be advantageous to record participants' actions during their activities in the computers in order to later identify both difficulties and patterns of game play and game creation (or modification).

Despite its limitations, the research conducted within this pilot study pointes to differences in knowledge acquisition and motivation influenced by constructionist/instructivist pedagogical strategies, which need to be explored in future research with a larger sample size. It would also be interesting to further investigate how the effects related to the pedagogical strategy used interact with the potential effects that age or school year has on knowledge acquisition and motivation.

\section{ACKNOWLEDGMENTS}

We would like to thank CESIS (Centre for Social Intervention Studies), in particular its team from the project "Percursos Acompanhados", for accommodating the study and making it logistically possible, a special thank you to Isa Monteiro and Marli Godinho for their support and kindness. Thank you also to the participants for attending the activities and their families for authorizing it. Thank you to Rahul Banerjee, research assistant at Center for Game Science, Washington University, and developer of Blockstud.io, for his readiness and kindness in our valuable discussions about the software's limitations and potential. Thank you to Leonor Duarte and José Falcão, primary school teachers, for our conversations, and their input on the written tests and games created for the study. Thank you to José Duarte and Ana Guedes for our analytical discussions about data treatment and presentation. We would also like to thank Instituto de Educação of Universidade do Minho and FCT (Foundation for Science and Technology), Portugal, for financing this study.

\section{REFERENCES}

[1] Y. B. Kafai, "Playing and Making Games for Learning: Instructionist and Constructionist Perspectives for Game Studies," Games Cult., vol. 1, no. 1, pp. 36-40, 2006.

[2] A. Baytak and S. M. Land, "A case study of educational game design by kids and for kids," Procedia - Soc. Behav. Sci., vol. 2, no. 2, pp. 5242-5246, 2010.

[3] N. Vos, H. van der Meijden, and E. Denessen, "Effects of constructing versus playing an educational game on student motivation and deep learning strategy use," Comput. Educ., vol. 56, no. 1, pp. 127-137, Jan. 2011.

[4] Y. T. Carolyn Yang and C. H. Chang, "Empowering students through digital game authorship: Enhancing concentration, critical thinking, and academic achievement," Comput. Educ., vol. 68, pp. 334-344, 2013.

[5] A. Baytak, S. M. Land, and B. K. Smith, "Children as educational computer game designers: An Exploratory study," Turkish Online J. Educ. Technol., vol. 10, no. 4, pp. 84-92, 2011.

[6] C. C. Navarrete, L. Minnigerode, and W. W. Workshop, "Exploring 21 st Century Learning: Game design and creation, the students experience Cesar C . Navarrete, University of Texas at Austin," 2013.

[7] Y. B. Kafai, M. L. Franke, C. C. Ching, and J. C. Shih, "Game design as an interactive learning environment for fostering students' and teachers' mathematical inquiry," Int. J. Comput. Math. Learn., vol. 3, no. 2, pp. 149-184, 1998.

[8] Center for Game Science (University of Washington), "Treefrog Treasure." [Online]. Available: http://centerforgamescience.org/blog/portfolio/treefrog-treasure/. [Accessed: 08-Jan-2016].

[9] Center for Game Science (University of Washington), "BlockStudio." [Online]. Available: http://centerforgamescience.org/blog/portfolio/blockstudio/. [Accessed: 08-Jan-2016]. 